\title{
ERRATUM
}

O. M. Keane · C. J. Dorman

\section{The gyr genes of Salmonella enterica serovar Typhimurium are repressed by the factor for inversion stimulation, Fis}

Published online: 21 August 2003

(C) Springer-Verlag 2003

\section{Mol Gen Genomics (2003)}

DOI 10.1007/s00438-003-0896-1

Owing to an unfortunate oversight by the publisher, the uncorrected version of Fig. 5 was published. dx.doi.org/10.1007/s00438-003-0896-1

O. M. Keane · C. J. Dorman $(\bowtie)$ Department of Microbiology, Moyne Institute of Preventive

Medicine, University of Dublin, Trinity College, Dublin 2, Ireland E-mail: cjdorman@tcd.ie

Tel.: + 353-1-6082013

Fax: + 353-1-6799294 
(A)
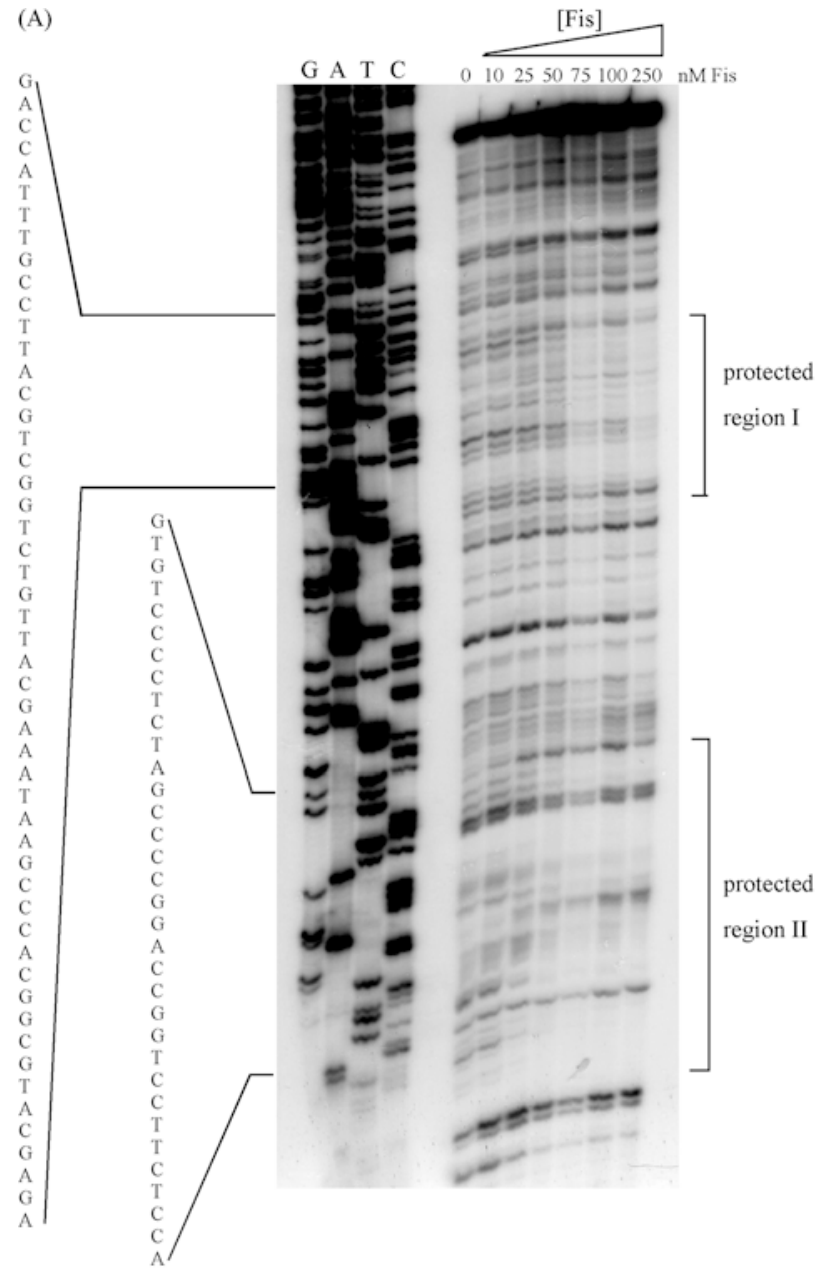

(B)

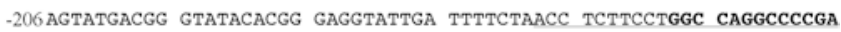
-146 TCTCCCCTGT GTCGCCTCTG AAGCCGATCG CCAATAAACG CCGAGACCAC GCTTATAAAT -86 GAAGAGAGCA TGCGGCACCC GAATAAAGCA TTGTCTGGCT GCATTCCGTT TACCAGTACG -26 TGGGCGAATG TGTTATAATT TGCGACCTTT GAATCCGGGA TACAGTAGAG GGATAGCGGT

Fig. 5A-D DNase I footprinting of Fis binding sites at the gyr $A$ and $\operatorname{gyr} B$ promoters. Radiolabelled $\operatorname{gyr} A(\mathbf{A})$ or $\operatorname{gyr} B(\mathbf{C})$ promoter DNA was incubated with increasing concentrations of Fis protein prior to digestion with DNase I. The regions protected by Fis from digestion are indicated by the brackets. The gyr $A$ sequence ladder was generated with oligonucleotide primer DNasegyrAF (A) and that for $g y r B$ with DNasegyrBPF (C). The Fis-DNA interactions are summarized by underlining in the sequences upstream of gyr $A$ (B) and $\operatorname{gyr} B$ (D). Sequences with matches to the consensus for Fis binding sites are indicated in bold, Pribnow boxes are shown in italics 